\title{
REPRESENTAÇÕES PARA PROFESSOR EM ARTIGOS DE OPINIÃO JORNALÍSTICOS SOB A PERSPECTIVA SISTÊMICO-FUNCIONAL
}

\author{
REPRESENTATIONS FOR TEACHERS IN \\ JOURNALISTIC OPINION ARTICLES UNDER A SYSTEMIC \\ FUNCTIONAL PERSPECTIVE
}

\begin{abstract}
Nédilã Espíndola Chagas Universidade Federal de Santa Maria, Santa Maria, Rio Grande do Sul, Brasil nedila.espindola.chagas@gmail.com

Ana Paula Carvalho Schmidt Universidade Federal de Santa Maria, Santa Maria, Rio Grande do Sul, Brasil ana-gcarvalho@hotmail.com
\end{abstract}

Resumo: O presente artigo tem por objetivo analisar as representações para professor e seus referentes em artigos de opinião de autoria de professores, publicados no blog Educação e Mídia, que é parte do conteúdo oferecido pela versão online do periódico paranaense Gazeta do Povo. Para tanto, tomamos por pressuposto teórico a Linguística Sistêmico-Funcional (HALLIDAY, 2014), mais especificamente o sistema de transitividade que realiza a metafunção ideacional, muito embora também tenhamos recorrido à metafunção interpessoal. A análise nos possibilitou observar que aos professores são manifestadas diferentes representações das quais se destacam a de responsável pelo processo de ensino e aprendizagem e pelas relações afetivas que repercutem na formação do educando como cidadão.

Palavras-chave: Linguística Sistêmico-Funcional; Representações; Professor; Artigo de Opinião

Abstract: This article aims at analyzing the representations for teacher and its referents in opinion articles written by teachers, published in the Educação e Mídia blog, which is part of the online version of the Gazeta do Povo newspaper. The analysis is based on the theoretical framework of Systemic Functional Linguistics (HALLIDAY, 2014), specifically on the transitivity system of the ideational metafunction, although we have also used the interpersonal metafunction. The results show the construction of different representations for teachers, such as responsible for the process of teaching and learning and for the establishment of an affectionate relationship with students that will influence their education as citizens.

Keywords: Systemic Functional Linguistics; Representations; Teacher; Opinion Article 


\section{INTRODUÇÃO}

No sistema educacional, professores são profissionais que acompanham o desenvolvimento dos estudantes desde a infância, no ensino fundamental, até a adolescência, no ensino médio. Também fazem parte da vida de muitos adultos que dão continuidade aos seus estudos, seja na modalidade da Educação de Jovens e Adultos ou no ensino superior. Devido a essa participação essencial e constante dos professores no processo formativo de indivíduos, um número considerável de estudos tem sido dedicado à investigação de representações, ou seja, "o sentido construído a partir de escolhas linguísticas" (SILVA; ESPÍNDOLA, 2016, p. 152), para a profissão docente. Nesses estudos, geralmente, questiona-se quem é o professor e qual o seu papel a partir da perspectiva de um determinado grupo social.

Tradicionalmente, o papel do professor tem sido definido como "uma figura de autoridade que decide o que deve ser aprendido e qual a melhor forma de aprendizagem" ou, ainda, como um "organizador de atividades" (TUDOR, 1993, p. 24, tradução nossa). Adicionalmente a essa representação do professor como responsável pelo ensino, os resultados obtidos por Veçossi e Corrêa (2012), com professores em formação de língua portuguesa, revelam diferentes representações para professor, tanto como aquele que disciplina os alunos quanto o que resgata "o caráter político na juventude" ou, ainda, uma espécie de "faz-tudo" (p. 22). Também enfocando o discurso de futuros professores de português, Ribeiro (2014) encontra a representação da profissão docente como uma trajetória "marcada por sofrimento, fobia, apreensão" (p. 114).

Além das representações construídas pelos próprios professores, em formação ou em serviço, outros atores sociais contribuem para a elaboração de representações para a profissão. Por exemplo, a tese de Borin (2012) investiga textos produzidos e veiculados pelo governo direcionados ao professor. A pesquisa demonstra que o professor é representado como alguém que precisa de auxílio para lecionar, um reprodutor de comandos ditados pelo material didático. Destacamos também o trabalho de Figueiredo e Bonini (2017) em que os autores, de uma perspectiva crítica, analisam textos veiculados na mídia que constroem representações negativas da profissão docente.

Entretanto, em rápida pesquisa realizada em bancos de dados de periódicos qualificados de Linguística e em bancos de teses, verificamos possível escassez de trabalhos sobre as representações construídas por professores para a profissão docente, em textos midiáticos, a partir de uma análise linguisticamente embasada. Por esse motivo, no presente trabalho, buscamos identificar representações léxico-gramaticais para o lexema professor e seus referentes, em artigos de opinião de autoria de professores, publicados no blog Educação e Mídia da Gazeta do Povo online.

Para apresentar a trajetória de pesquisa, organizamos o trabalho, além desta introdução, em quatro seções. Primeiramente, uma seção de fundamentação teórica, na qual explicamos conceitos centrais para a análise. Em segundo lugar, na metodologia, descrevemos os critérios de seleção dos textos, a constituição do corpus e os procedimentos de análise. A seguir, interpretamos e discutimos os dados gerados e, por fim, elaboramos considerações sobre o trabalho realizado.

\section{PRESSUPOSTOS TEÓRICOS}

\footnotetext{
${ }^{1}$ Todas as traduções neste artigo são de nossa responsabilidade. No original: “(...) the teacher is a figure of authority who decides on what should be learned and how this should best be learned. The second role is that of activity organizer (...)".
} 
Recorremos ao suporte teórico da Linguística Sistêmico-Funcional (doravante, LSF), especificamente da Gramática Sistêmico-Funcional (HALLIDAY, 2014) para a seleção e organização de categorias de análise. Nesse quadro teórico, o funcionamento da linguagem em contextos de uso é central e as interações sociais mediadas pela linguagem são vistas como escolhas efetuadas pelo falante/escritor, dentre opções disponibilizadas no sistema linguístico, a fim de alcançar determinados propósitos, em contextos específicos.

Tais escolhas estão imersas em um âmbito social mais amplo, o contexto de cultura. E, em um aspecto mais restrito, essas escolhas também fazem parte do ambiente imediato em que um texto funciona, o contexto de situação (HALLIDAY, 2014). De acordo com Halliday (2014, p. 33), o contexto de situação compreende três variáveis: campo, relações e modo, que dão conta respectivamente do que está acontecendo, de quem participa, das relações estabelecidas entre os participantes e do papel desempenhado pela linguagem e outros sistemas semióticos em uma dada situação social. Essas variáveis serão utilizadas na composição dos resultados, pois auxiliarão na descrição do contexto de produção dos textos analisados.

Para a LSF, a língua se organiza em torno de redes que correspondem a funções básicas da linguagem. Halliday (2014) nomeia essas funções de metafunções para diferenciá-las de "função" enquanto uso da linguagem para atingir um determinado objetivo comunicativo, por exemplo aceitar e recusar convites, e para "sugerir que função é um componente central na teoria como um todo ${ }^{2 "}$ (p. 31). Esse linguista propõe três funções ou metafunções desempenhadas, concomitantemente, pela linguagem: ideacional, usada para representar a vivência e experiência de mundo; interpessoal, para codificar papéis e relações sociais na interação; textual, que reúne os significados ideacionais e interpessoais para a construção, organização e desenvolvimento da mensagem (HALLIDAY, 2014).

Para cumprir o objetivo deste trabalho, de analisar linguisticamente as representações construídas para professor em artigos de opinião sobre educação, utilizaremos recursos do sistema de transitividade. Nesse sistema, a oração é descrita como uma configuração de um processo (que pode ser material, mental, verbal, relacional, comportamental ou existencial), participantes e circunstâncias, os quais formam "figuras", diferenciadas de acordo com os tipos de classificação desses processos (MATTHIESSEN; HALLIDAY, 2009; HALLIDAY, 2014).

Tipicamente representados por verbos (FUZER; CABRAL, 2014), os processos representam eventos que constituem domínios da experiência (HALLIDAY, 2014), atividades humanas realizadas no mundo. Há três tipos de processos, considerados principais, pelos quais a experiência humana é linguisticamente representada, materiais, mentais e relacionais. Os demais, considerados secundários, situam-se na fronteira entre esses três processos, pois apresentam características comuns a mais de um desses processos. $\mathrm{O}$ uso de processos materiais representa a experiência externa, ações e eventos, enquanto, por outro lado, os mentais representam a experiência interna, de cognição, emoção. Os relacionais, por sua vez, representam relações de identificação e caracterização. Já os processos comportamentais são mobilizados para representar comportamentos. Processos verbais representam atividades linguísticas dos participantes e, por fim, processos existenciais representam a existência ou acontecimento de algo.

Justificamos a seleção do gênero argumentativo artigo de opinião por conter, caracteristicamente, avaliações semânticas do autor, direcionadas para influenciar os leitores, que podem ser "remodelada[s] como um processo gramatical"3 (MARTIN; WHITE, 2005, p. 11), por meio da seleção de um tipo de processo do sistema de transitividade. $\mathrm{O}$ artigo de opinião pode ser escrito a partir de uma situação-problema que apresente uma questão a ser

\footnotetext{
${ }^{2}$ No original: "( $(.$.$) to suggest that function was an integral component within the overall theory (...)"$

${ }^{3}$ No original: “(...$)$ reworked as a grammatical process (...)”
} 
desenvolvida por meio de argumentos que sustentem a discussão e levem a uma apreciação ou reafirmação do tema. Além disso, apresenta, geralmente, o ponto de vista de indivíduos que não exercem função profissional na imprensa, constituindo-se um gênero que "democratiza a opinião no jornalismo" (MELO, 1994, p. 122), pois dá voz a representantes de diversos setores da sociedade civil.

A partir do embasamento teórico descrito anteriormente, delimitamos os procedimentos metodológicos para constituição e análise do corpus, os quais detalharemos na próxima seção.

\section{METODOLOGIA}

Foram selecionados artigos de opinião, publicados no blog Mídia e Educação, que faz parte do conteúdo oferecido online pelo periódico Gazeta do Povo. Nesse espaço são publicados textos de diversos autores, educadores, jornalistas, economistas, entre outros profissionais, que abordem, de alguma forma, o tema educação.

O corpus foi delimitado a partir dos seguintes critérios: 1) título que contivesse as palavras-chave educação ou educador; 2) autorados por professores 3) período de publicação: janeiro de 2013 a junho de 2017. O terceiro critério foi inicialmente delimitado a partir das eleições de 2014, que trouxeram propostas de modificações, em nível estadual e federal, com relação à legislação que rege questões ligadas à educação. Entretanto, como identificou-se a ausência de textos autorados por professores na fonte de coleta do corpus, ampliamos em um ano o período de coleta de dados. Assim, foi possível obtermos quatro artigos de opinião. No Quadro 1, apresentamos dados do contexto de produção dos artigos, tais como título, autor, fonte e data de publicação.

Quadro 1- Corpus de análise

\begin{tabular}{|c|c|c|c|c|}
\hline Cód & Título & Autor & Fonte de publicação & $\begin{array}{c}\text { Data } \\
\text { de publicação }\end{array}$ \\
\hline$T 1$ & $\begin{array}{l}\text { Tecnologias na educação: é } \\
\text { preciso mudar a } \\
\text { metodologia, não só as } \\
\text { ferramentas. }\end{array}$ & $\begin{array}{l}\text { Guilherme } \\
\text { Lemermeier } \\
\text { Rodrigues }\end{array}$ & $\begin{array}{l}\text { https://www.gazetadopov } \\
\text { o.com.br/blogs/educacao- } \\
\text { e-midia/tecnologias-na- } \\
\text { educacao-e-preciso- } \\
\text { mudar-a-metodologia-nao- } \\
\text { so-as-ferramentas/ }\end{array}$ & $21 / 06 / 2016$ \\
\hline$T 2$ & $\begin{array}{l}\text { A educação escolar da } \\
\text { criança e seus novos } \\
\text { contextos }\end{array}$ & $\begin{array}{c}\text { Andreane Tecchio } \\
\text { Motta }\end{array}$ & $\begin{array}{l}\text { https://www.gazetadopov } \\
\text { o.com.br/blogs/educacao- } \\
\text { e-midia/a-educacao- } \\
\text { escolar-da-crianca-e-seus- } \\
\text { novos-contextos/ }\end{array}$ & $24 / 02 / 2015$ \\
\hline$T 3$ & $\begin{array}{l}\text { A educação em ponto } \\
\text { morto? }\end{array}$ & Acedriana Vicente & $\begin{array}{c}\text { https://www.gazetadopov } \\
\text { o.com.br/opiniao/artigos/a } \\
\text { educacao-em-ponto- } \\
\text { morto- } \\
\text { 44ayhktc1ztu369u2ykqhw } \\
\text { o1s }\end{array}$ & $06 / 01 / 2017$ \\
\hline$T 4$ & $\begin{array}{l}\text { Educador: construtor do } \\
\text { invisível. }\end{array}$ & Luciano Diniz & $\begin{array}{l}\text { https://www.gazetadopov } \\
\text { o.com.br/blogs/educacao- } \\
\text { e-midia/educador- } \\
\text { construtor-do-invisivel/ }\end{array}$ & $07 / 02 / 2013$ \\
\hline
\end{tabular}

Fonte: elaborado pelas autoras. 
O terceiro critério contribuiu para o reduzido número de artigos selecionados. Disso, inferimos que profissionais de áreas não relacionadas à educação se manifestam e veiculam suas impressões sobre esse campo do conhecimento no blog em questão em maior proporção que os próprios professores.

\subsection{PROCEDIMENTOS DE ANÁLISE DE DADOS}

Para a análise linguística, utilizamos a perspectiva da LSF (HALLIDAY, 2014), com base na metafunção ideacional, em específico o sistema de transitividade. Foram observados os tipos de processos recorrentes e a função desempenhada pelo item lexical professor apenas como núcleo de participante, por serem essas as entidades envolvidas que levam à ocorrência do processo ou são afetadas por ele. Posteriormente, foram analisadas as construções de representações para professor e seus referentes. Para tanto, seguimos os seguintes passos:

- Levantamento no corpus da palavra professor, incluindo seus referentes, os recursos coesivos utilizados no texto e elipses;

- Segmentação do texto em orações e identificação das funções léxico-gramaticais de cada constituinte do sistema de transitividade;

- Classificação dessas orações por tipo de processo;

- Leitura iterativa para interpretação das principais representações para professor, a partir das escolhas léxico-gramaticais de cada autor.

$\mathrm{Na}$ próxima seção, descrevemos a configuração contextual e apresentamos e discutimos a interpretação dos resultados obtidos a partir dos dados gerados.

\section{RESULTADOS E DISCUSSÃO}

Organizamos a descrição e análise dos resultados em duas partes interligadas: 1) contextual e 2) linguística. Primeiramente, o aspecto contextual será descrito sob duas perspectivas, apresentadas anteriormente, na seção de fundamentação teórica: como parte, simultaneamente, de um contexto de cultura e de um contexto de situação.

Com relação ao contexto de cultura, a mídia constitui o cenário de práticas institucionalizadas em que os artigos são produzidos. Com relação ao contexto de situação, na variável Campo, os autores usam o espaço na versão online do jornal para expressar seus pareceres sobre questões diversas ligadas à educação. Na variável Relações, os participantes da interação são os autores dos textos, professores, e os leitores do blog ou qualquer usuário das redes sociais que queira acessar o site. Por fim, quanto à variável Modo, o gênero é artigo de opinião, a modalidade é escrita, o canal é gráfico-visual e a internet é o veículo. No Quadro 2, detalhamos o campo, os participantes autores e o modo de cada artigo que compõe o corpus:

Quadro 2 - Contexto de situação: variáveis de registro do corpus

\begin{tabular}{cccc}
\hline Cód & Campo & Relações & Modo \\
\hline & O uso das novas tecnologias digitais & Autor: Guilherme Lemermeier & \\
T 1 & $\begin{array}{c}\text { como um meio de desenvolvimento } \\
\text { para novas metodologias. }\end{array}$ & $\begin{array}{c}\text { Rodrigues, licenciado em Matemática } \\
\text { e Mestre em Educação e professor }\end{array}$ & $\begin{array}{c}\text { Meio escrito, } \\
\text { canal gráfico na } \\
\text { internet. }\end{array}$ \\
& & universitário
\end{tabular}




\begin{tabular}{|c|c|c|c|}
\hline Т 2 & $\begin{array}{c}\text { Formar cidadãos na sociedade } \\
\text { contemporânea }\end{array}$ & $\begin{array}{c}\text { Autor: Andreane Tecchio Motta, } \\
\text { pedagoga. }\end{array}$ & $\begin{array}{l}\text { Meio escrito, } \\
\text { canal gráfico na } \\
\text { internet. }\end{array}$ \\
\hline T 3 & $\begin{array}{c}\text { A estagnação da educação brasileira } \\
\text { e o papel do professor nesse } \\
\text { contexto. }\end{array}$ & $\begin{array}{l}\text { Autor: Acedriana Vicente, pedagoga, } \\
\text { Mestre em Engenharia de Produção e } \\
\text { diretora pedagógica da Editora } \\
\text { Positivo. }\end{array}$ & $\begin{array}{l}\text { Meio escrito, } \\
\text { canal gráfico na } \\
\text { internet. }\end{array}$ \\
\hline T 4 & $\begin{array}{c}\text { O papel do professor e sua } \\
\text { contribuição para a sociedade. }\end{array}$ & $\begin{array}{l}\text { Autor: Luciano Diniz, coordenador da } \\
\text { pós-graduação em Educação Integral } \\
\text { Transformadora da Associação Gente } \\
\text { de Bem. }\end{array}$ & $\begin{array}{l}\text { Meio escrito, } \\
\text { canal gráfico na } \\
\text { internet. }\end{array}$ \\
\hline
\end{tabular}

Fonte: elaborado pelas autoras.

Feita a descrição do contexto de situação dos artigos, passamos à análise linguística. Os autores dos artigos de opinião utilizaram predominantemente, processos materiais (seis ocorrências), para expressar ações, e relacionais (cinco ocorrências), para expressar estados. Em menor quantidade, foram utilizados processos mentais (quatro ocorrências), para expressar sentimentos. Podemos inferir, portanto, que o professor não é representado de acordo com suas ideias, sentimentos, desejos ou percepções em relação à educação, mas por meio das ações que realiza e de suas características como educador. Esses tipos de processos ramificam-se em subtipos de processos, os quais são especificados no Quadro 3, juntamente com o número de ocorrências de cada um.

Quadro 3 - Quantificação de processos e subtipos de processos

\begin{tabular}{|c|c|c|c|c|}
\hline $\begin{array}{c}\text { Tipo de } \\
\text { processo }\end{array}$ & Subtipo de processo & $\begin{array}{l}\text { Número de } \\
\text { ocorrências }\end{array}$ & $\begin{array}{l}\text { Cód. } \\
\text { artigo de opinião }\end{array}$ & Exemplos \\
\hline \multirow{3}{*}{ material } & criativo geral & 3 & $\mathrm{~T} 2$ & $\begin{array}{c}{[\text { Nós, professores] precisamos }} \\
\text { inovar }(\ldots)\end{array}$ \\
\hline & $\begin{array}{l}\text { transformativo } \\
\text { de elaboração }\end{array}$ & 1 & $\mathrm{~T} 4$ & $\begin{array}{c}\text { Os educadores atuam com seus } \\
\text { alunos (...) }\end{array}$ \\
\hline & $\begin{array}{l}\text { transformativo de } \\
\text { extensão possessão }\end{array}$ & 2 & $\mathrm{~T} 4$ & $\begin{array}{c}\text { Cada educador pode contribuir } \\
\text { para a construção de belas } \\
\text { estruturas (...) }\end{array}$ \\
\hline \multirow{4}{*}{ relacional } & atributivo possessivo & 2 & $\mathrm{~T} 2$ & $\begin{array}{c}\text { O professor deve ter uma } \\
\text { pedagogia baseada na escuta }\end{array}$ \\
\hline & atributivo intensivo & 1 & $\mathrm{~T} 1$ & $\begin{array}{c}\dot{E} \text { importante preparar o professor } \\
(\ldots)\end{array}$ \\
\hline & $\begin{array}{l}\text { identificadora } \\
\text { intensiva }\end{array}$ & 1 & $\mathrm{~T} 2$ & $\begin{array}{c}\text { Ser educador na escola } \\
\text { contemporânea é lidar } \\
\text { diretamente com as mudanças (...) }\end{array}$ \\
\hline & circunstancial & 1 & $\mathrm{~T} 2$ & $\begin{array}{c}\text { [Nós, professores] estamos diante } \\
\text { de um novo cenário } \\
\text { socioeducacional }(. . .)\end{array}$ \\
\hline \multirow{2}{*}{ mental } & desiderativo & 1 & $\mathrm{~T} 2$ & $\begin{array}{l}\text { Se [nós, professores] queremos } \\
\text { resultados diferentes (...) }\end{array}$ \\
\hline & cognitivo & 3 & $\mathrm{~T} 3$ & $\begin{array}{l}\text { O professor tem, portanto, de } \\
\text { tocar esse aluno (...) }\end{array}$ \\
\hline
\end{tabular}

Fonte: elaborado pelas autoras.

A classificação das orações por tipo e subtipo de processo possibilitou a identificação e interpretação das representações construídas nos artigos de opinião para o lexema professor. Esse profissional é representado como: 1) participante ativo de constante aprimoramento; 2) 
mediador crítico no processo de ensino e aprendizagem; 3) resiliente em relação a mudanças; 4) focado nos alunos. A seguir, exemplificamos como cada representação é instanciada no estrato léxico-gramatical da linguagem.

\section{Aprendiz}

Tomando o primeiro texto para análise (T1), Tecnologias na educação: é preciso mudar a metodologia, não só as ferramentas, encontramos apenas uma ocorrência de professor como parte do participante, dentro do participante preparar o professor. Neste caso, o professor faz parte de um processo relacional.

(1) É importante preparar o professor para o uso das tecnologias digitais além do ferramental.

No excerto (1), “o professor” é representado como alguém que necessita de preparo para o uso de tecnologias digitais. Entendemos, então, que o profissional da educação atualmente não faz ou faz pouco uso desses recursos digitais, devido à sua falta de capacitação para elaborar propostas didáticas que envolvam o uso de tecnologias. Essa representação atribuída ao professor demonstra acompanhamento e utilização do avanço tecnológico aquém do necessário para o desempenho de suas funções, evidenciando uma caracterização desfavorável desse profissional. Temos, assim, a representação de um profissional com habilidades defasadas, ainda sem qualificação para o uso desses recursos na mediação da aprendizagem.

No T3, Educação em ponto morto?, o professor é Ator dos processos. Desse modo, temos que o professor está representado como agente atuante no processo educacional. No trecho a seguir, o excerto (2) traz o professor como Ator de um processo material, sendo-lhe atribuída a tarefa de melhoramento das metodologias de ensino.

(2) Está cada vez mais claro que o professor em sala de aula precisa aperfeiçoar metodologias de ensino para assegurar o direto de aprender.

Na oração "o professor em sala de aula precisa aperfeiçoar metodologias de ensino", o professor exerce um papel ativo no processo de ensino e aprendizagem. Observamos, ainda, o recurso interpessoal de modalidade, por meio do processo "precisa", que estabelece um alto grau de obrigação à função de aperfeiçoar as metodologias, o que torna tal habilidade parte indispensável à atividade docente.

No excerto (3), "os professores" é Fenômeno de um processo mental, no qual sofrem a avaliação de outros professores ou alunos. Sua representação é de objeto de apreciação.

(3) Os professores são avaliados em plena sala de aula por outros professores e pelos próprios alunos.

Além das avaliações explícitas, realizadas léxico-gramaticalmente por adjetivos e advérbios, processos materiais ou processos verbais também podem ser utilizados para manifestações avaliativas sobre algo. No excerto (3), por exemplo, há a caracterização da avaliação como uma atividade mental de percepção do trabalho do professor, por colegas de profissão - "outros professores" e alunos, pois estes não costumam se utilizar de instrumentos avaliativos explícitos para valorar o trabalho do professor. 
A seguir, encontramos "professores" como Experienciador de um processo mental cognitivo que retrata a experiência de aprendizagem dos professores.

(4) O desafio começa acreditando que não se pode continuar ensinando da forma como os professores aprenderam.

Tal aprendizagem é descartada a fim de abrir espaço, dentro do sistema que deve conduzir a educação na atualidade, para novas formas de ensino e aprendizagem. Nesse caso, o professor deixa de ser identificado apenas como o indivíduo que ensina, mas é reconhecido igualmente como um ser que necessita aprender sobre as abordagens de ensino contemporâneas, representado, portanto, como aprendiz.

\section{Mediador}

O T4, Educador: construtor do invisivel, apresenta o professor em três ocorrências como participante de orações. Nesse texto, o termo usado para referir-se ao professor é educador, conforme já demonstra o título.

(5) os educadores atuam com seus alunos sem poder ver todos os frutos da sua obra.

No excerto (5), "os educadores" são representados como aqueles que agem e desenvolvem ações concernentes à atividade docente, em cooperação "com seus alunos". A ação se dá em conjunto com os alunos, porém, o professor não consegue vislumbrar ("sem poder ver") resultados imediatos de seu trabalho como formador.

No excerto (6), a seguir, "cada educador" é Ator do processo material contribuir, salientando a sua colaboração na vida dos alunos.

(6) Nesse aspecto, mais sutil, cada educador pode contribuir para a construção de belas estruturas, que auxiliarão na sustentação da vida desse sujeito (...)

O processo "contribuir" aparece modalizado pelo verbo "poder", o que evidencia a probabilidade de que essa contribuição ocorra ou não. A representação para "educador", portanto, é de mediador na edificação do aluno como sujeito e cidadão.

(7) Por outro lado o educador também pode levantar muros que impedem seu aluno de avançar, que bloqueiam sua criatividade, talentos e potencialidade.

No excerto (7), "o educador" é o Ator do processo material "levantar", uma metáfora ideacional, que nesta proposição traduz a ação de construir barreiras para a aprendizagem. A representação evidenciada para educador é a de interventor no processo de ensino e aprendizagem de forma negativa, impedindo um desenvolvimento criativo do aluno.

No excerto (8), o professor é, juntamente com outros participantes citados (pais, alunos, dentre outros), Ator do processo material "oferecer".

(8) Esses diferentes saberes, de diferentes vertentes e origens, são convidados ao diálogo para que juntos, alunos, professores, pais, (...) possam oferecer novos e variados elementos para ajudar na formação integral do aluno. 
Assim, o professor é representado como um formador, participando do desenvolvimento integral dos alunos por meio de diferentes e variados elementos. $\mathrm{O}$ verbo modal "possam", que acompanha o processo "oferecer", é um recurso léxico-gramatical que, nesse caso, evidencia que auxiliar na formação do aluno é uma das possibilidades de atuação do professor e não uma obrigatoriedade.

(9) O gosto pela investigação, a curiosidade, são características humanas que devem fertilizar as estratégias para aprender, além de serem cultivadas pelo professor pelo fato de ser a base do pensamento criativo, tão exigido no mundo do trabalho.

Neste trecho (9), "o professor" é aquele que cultiva, alguém que age no processo de aprendizagem por meio do interesse pela investigação e curiosidade. Nesse caso, em específico, a expressão cultivar ${ }^{4}$, que a princípio se refere ao trabalho com a terra, indicando o ato de lavrar, hortar; aqui toma significado de dedicar-se, interessar-se por práticas que colaboram com o desenvolvimento de habilidades necessárias ao mundo do trabalho.

\section{Resiliente}

No excerto (10), "ser educador" é o Portador de um processo relacional e tem como Atributo uma oração encaixada não finita "lidar diretamente com as mudanças que ocorrem na prática profissional".

(10) Portanto, ser educador na escola contemporânea é lidar diretamente com as mudanças que ocorreram na prática profissional, como consequência das mudanças do ser humano e do mundo, ao mesmo tempo.

O educador, sabendo trabalhar com alterações, modificações, relacionadas a sua profissão, é representado como um profissional apto a lidar com as transformações da sociedade que repercutem no seu ofício, visto que é representado como alguém que lida diretamente com as mudanças ocorridas na prática profissional.

\section{Focado no aluno}

No T2, A educação escolar da criança e seus novos contextos, encontramos três orações nas quais o professor aparece como participante dos processos. Em cada ocorrência ele exerce uma função distinta: Possuidor, Ator e Portador.

(11) O professor, hoje, deve ter uma pedagogia baseada na escuta, no interesse do aluno, na acolhida e no diálogo.

No excerto (11), “o professor" é o Possuidor no processo relacional possessivo "ter". Atentamos para a representação de detentor de uma pedagogia embasada na acolhida e no diálogo, pois deverá basear-se na escuta e no interesse do aluno. As metáforas gramaticais (nominalizações) demonstram que o professor exerce implícita e simultaneamente a função de Receptor (escuta), Dizente e Receptor (diálogo)

\footnotetext{
${ }^{4}$ Cultivar (cul.ti.var) v. 1. Arg. Bot. Efetuar a fertilização da terra pelo trabalho de revirá-la, regá-la, etc. (CALDAS, 2011, p. 424).
} 
Além disso, observamos a ocorrência do verbo modalizador "deve", indicando um alto grau de obrigação. Por meio da função interpessoal, o autor demonstra sua inclinação em recomendar que o professor exerça seu fazer pedagógico da forma como ele propõe.

No excerto (12), "o professor" (em elipse) é Portador de um processo relacional, a quem é atribuída a capacidade de efetivar a aprendizagem. Nesse processo, por meio da metafunção interpessoal, identificamos o ponto de vista do autor, a partir da escolha do verbo deve, como recurso de modulação.

\section{(12) [O professor] Deve ser capaz de fazer qualquer aluno aprender...}

Nesse caso, a modulação por meio do comando "deve" é uma metáfora interpessoal por ser alterativa ao modo imperativo que, de fato, indica o comando. Atribui, assim, a obrigação de efetivar a aprendizagem de qualquer aluno, ou seja, de todos os alunos, independentemente de particularidades e desconsiderando os inúmeros fatores que compõem o processo de ensino e aprendizagem e interferem no mesmo.

\section{(13) O professor, precisa, portanto, tocar esse aluno,}

No excerto (13), o professor é Ator do processo mental "tocar", que lhe incumbe da tarefa de aproximar-se do aluno afetivamente, agindo de modo a sensibilizá-lo. O uso do operador modal "precisa" no Finito indica uma obrigação, servindo aos significados interpessoais da oração ao expressar um posicionamento do autor. Nesses termos, a relação afetiva entre professor e aluno aparece como fundamental para um resultado positivo do processo educativo que vai além da transmissão de conhecimento e resulta em formação de cidadãos críticos e inovadores, capazes de contribuírem para melhorias no quadro social.

\section{(14) [O professor] entendendo que seu trabalho está a serviço da formação de} cidadãos críticos e inovadores.

Verificamos, no excerto (14), que há uma projeção do processo mental cognitivo "entender". Aqui, o "professor" é Experienciador na oração projetada e sua representação é de profissional consciente da função que desempenha por meio de seu trabalho e da responsabilidade por fomentar a discussão e reflexão acerca de diferentes pontos de vista sobre um mesmo tópico. Ao evocar a criticidade como elemento constituinte da cidadania, o autor do artigo de opinião defende que cabe aos professores planejar atividades que estimulem os estudantes a refletir sobre o contexto em que estão inseridos a fim de se engajarem em ações em prol de uma sociedade mais justa (FREIRE, 2011).

\section{CONSIDERAÇÕES FINAIS}

Este trabalho propôs a análise das representações de professor em artigos de opinião produzidos por professores e veiculados na mídia, por meio de uma análise linguística, com suporte nas categorias léxico-gramaticais do sistema de transitividade que realizam a metafunção ideacional experiencial da linguagem (HALLIDAY, 2014).

Nossa análise concentrou-se em quatro textos de autoria de professores, publicados no blog Mídia e educação, entre 2013 e 2017, contrariando nossa expectativa inicial de que encontraríamos um número significativo de textos. Primeiramente, observamos presença pouco expressiva de "professor" como participante nas orações. Nas ocorrências encontradas como participante, a análise demonstra que "professor" é Ator em sete processos materiais, dos quais 
três deles dizem respeito à sua prática profissional e os outros quatro, ao relacionamento com o educando e sua formação como sujeito social. Interpretamos dessa constatação que as representações de professor enquanto Ator nesses processos é, no primeiro caso, de responsável pelo ensino e pela aprendizagem do aluno, seu sucesso ou infortúnio de acordo com a categoria de análise "mediador". No segundo caso, sua representação é de responsável pelas relações aluno/professor que influenciam positiva ou negativamente na formação do aluno enquanto cidadão, para o qual evidenciamos a categoria "focado no aluno". Entendemos ambas representações como uma ratificação da importância da atuação dos professores na sociedade. Estas representações podem contribuir para o entendimento da relevância do profissional da educação pela sociedade em geral e, em particular, pelos leitores do periódico Gazeta do Povo. Tais representações assinalam que o papel do professor transcende a disseminação dos conhecimentos científicos e abrange a formação de sujeitos conscientes de seus deveres e direitos perante a sociedade.

Em cinco orações, identificamos o professor como participante de processo relacional. Como Portador, o professor aparece em dois momentos. Primeiramente, em uma oração atributiva intensiva, ao caracterizar a Entidade "professor". Em um segundo momento, em uma oração circunstancial. Por meio da análise dessas ocorrências, consideramos que o professor, como Portador, é representado como alguém capaz de agir habilidosamente com as modificações que ocorrem em sua profissão decorrentes das transformações do mundo. Em outras duas ocorrências como Possuidor, observa-se a relação de posse entre as entidades. Como Possuidor, é representado como detentor de determinado tipo de pedagogia, sendo esse processo modalizado deonticamente, incutindo ao professor a obrigatoriedade de identificar-se com uma determinada abordagem de ensino e aprendizagem. Em adição, como Identificado, de acordo com a categoria "resiliente", é representado como um profissional com capacidade para efetivar o processo de ensino e aprendizagem. Observamos que tais representações atribuem ao professor características que o qualificam positivamente, à medida que reforçam sua capacidade de atuar com conhecimento e eficácia. Observamos que, mais uma vez, há um destaque para importância da atuação do professor, corroborando com as representações iniciais que constituíam uma imagem positiva para este profissional.

Ademais, observamos para professor a representação de "aprendiz", enquanto Experienciador, em relação às antigas metodologias e também de profissional ciente do papel que desempenha em sua função como educador. No processo em que ele é um sujeito que tem compreensão sobre sua função, entendemos que essa representação reforça sua responsabilidade profissional. No processo em que é aprendiz, observamos um descarte de sua experiência enquanto educando, sendo essa rechaçada como modelo para a educação na atualidade. Em um único momento encontramos referência ao professor de forma pejorativa, enquanto Meta no processo, cuja condição de profissional capacitado é questionada, visto aparecer em situação de despreparo para usar novas tecnologias. Nesse caso, o professor necessita buscar o aperfeiçoamento de sua formação, evidenciando a representação de "aprendiz".

Em suma, das diversas representações encontradas nos textos, as que mais se destacam são as representações do professor como sujeito atuante no exercício de suas atividades pedagógicas, mediador, e na construção de um bom relacionamento, focado nos alunos, sendo, desse modo, responsabilizado não apenas pela efetivação do processo de aprendizagem, mas também pela formação de cidadãos. Ao observamos um maior número de representações que ratificam a importância do profissional da educação, entendemos, que apesar de algumas restrições feitas à sua atuação e suposto despreparo para as tecnologias, os leitores dos artigos de opinião sobre os quais voltamos nosso olhar, podem auferir percepções 
favoráveis e esclarecidas sobre a atuação do professor, as quais entendemos como necessárias para o despertar de um processo de valorização dos professores.

\section{REFERÊNCIAS}

BORIN, M. A. As representações sobre professor em material distribuído pelas instâncias governamentais: uma possível leitura. 2012. 159 p. Tese (Doutorado em Letras - Estudos Linguísticos). Universidade Federal de Santa Maria, Santa Maria, 2012.

CALDAS, A. Novíssimo Aulete dicionário contemporâneo da Língua Portuguesa. Rio de Janeiro: Lexikon, 2011.

FIGUEIREDO, D. C.; BONINI, A. Recontextualização e sedimentação do discurso e da prática social: como a mídia constrói uma representação negativa para o professor e para a escola pública. DELTA, São Paulo, v. 33, n. 3, p. 759-786, Set. 2017. DOI: https://doi.org/10.1590/0102-445099800747799785.

FREIRE, P. Pedagogia do oprimido. Rio de Janeiro: Paz e Terra, 2011.

FUZER, C.; CABRAL, S. R. S. Introdução à gramática sistêmico-funcional em língua portuguesa. Campinas, SP: Mercado de Letras, 2014.

HALLIDAY, M. A. K. Halliday's introduction to functional grammar. Revisado por Christian Matthiessen. $4^{\text {a }}$.ed. Londres: Routledge, 2014.

MATTHIESSEN, C. M. I. C; HALLIDAY, M. A. K. Systemic Functional Grammar: a first step into the theory. Pequim: Higher Education Press, 2009.

MARTIN; J. R.; WHITE, P. R. R. The Language of Evaluation: appraisal in English. Londres: Palgrave/Macmillan, 2005.

MELO, J. M. de. A opinião no jornalismo brasileiro. Petrópolis: Vozes, 1994.

RIBEIRO, P. B. Representações do ser professor no curso de Letras. Revista do GEL, São Paulo, v. 11, n. 2, p. 97-116, 2014.

SILVA, W. R.; ESPÍNDOLA, E. Professor da escola básica representado na escrita reflexiva acadêmica do aluno mestre. Alfa, São Paulo, v. 60, n. 1, p. 147-173, 2016.

TUDOR, I. Teacher roles in the learner-centred classroom. ELT Journal, v. 4711, p. 22-31 jan. 1993.

VEÇOSSI, C. E.; CORRÊA, M. C. Representações do agir docente em textos de acadêmicos de um curso de licenciatura em Letras. Letras, Santa Maria, v. 22, n. 44, p. 11-26, jan./jun. 2012.

Recebido em: 16 de fevereiro 2019

Aceito em: 05 de setembro de 2019

Publicado em Maio de 2020 